\title{
DNA Damage by Endogenous and Exogenous Aldehydes
}

\author{
Marisa H. G. Medeiros ${ }^{\circledR} *, a$ \\ ${ }^{a}$ Departamento de Bioquímica, Instituto de Química, Universidade de São Paulo, \\ 05508-000 São Paulo-SP, Brazil
}

\begin{abstract}
The present overview describes the formation of deoxyribonucleic acid (DNA) adducts from endogenous and exogenous aldehydes, such as acetaldehyde, acrolein, crotonaldehyde, malonaldehyde, 4-hydroxy-2-nonenal and 2,4-decadienal. Malonaldehyde reacts with 2'-deoxyguanosine, 2'-deoxyadenosine, and 2'-deoxycytidine, yielding cyclic pyrimidopurinone and acyclic adducts. The direct addition of $\alpha, \beta$-unsaturated aldehydes to DNA bases yields cyclic substituted propano adducts, such as $1, N^{2}$-propano-2'-deoxyguanosine. Alternatively, $\alpha, \beta$ unsaturated aldehydes can be oxidized to reactive epoxides, giving ethano or etheno derivatives upon reaction with DNA. In addition, information on highly sensitive techniques, employed for the in vivo detection and quantification of DNA-aldehyde adducts, is also provided. Some of these DNA-aldehyde lesions have been shown to be highly mutagenic. In fact, lipid peroxidation and exogenous aldehyde exposure could potentially account for the observed carcinogenicity of urban air pollution and cigarette smoke exposure.
\end{abstract}

Keywords: aldehydes, DNA adducts, DNA damage

\section{Introduction}

The integrity and stability of genetic information is crucial for maintaining life. However, deoxyribonucleic acid (DNA) is not inert and has numerous sites for chemical interaction. For example, various types of DNA lesions, resulting from attack on nitrogenous bases, 2'-deoxyribose residues and phosphodiester bonds, have been reported. ${ }^{1}$ It is estimated that the DNA in a single cell can undergo up to one million changes per day. ${ }^{2}$ In fact, various sources including UV radiation, ionizing radiation, as well as genotoxic agents present in the air, food and cigarette smoke have been shown to modify DNA.

Aldehydes are known to react with and modify DNA. These compounds are widespread in the environment, and are present in foods, beverages, cigarette smoke, and are also formed through the combustion of wood, coal, alcohol and diesel fuels. ${ }^{3}$ Exogenous aldehydes, such as acrolein, 2,4-nonadienal and 2-pentenal, are also formed during the cooking of fats, oils, and sugars. ${ }^{4}$ Aldehydes are produced endogenously, primarily, by the lipid peroxidation, which produces a large number of reactive aldehydes. Many of these aldehydes react with biomolecules such as DNA, proteins and amino acids, ultimately resulting in a variety

*e-mail:mhgdmede@iq.usp.br of diseases and cytotoxic effects, and contributing to the aging process (Figure 1). ${ }^{5,6}$

Aldehydes are capable of modifying DNA and yielding promutagenic lesions, which may, at least partially, account for the observed mutagenic and carcinogenic effects associated with the lipid peroxidation process and urban air

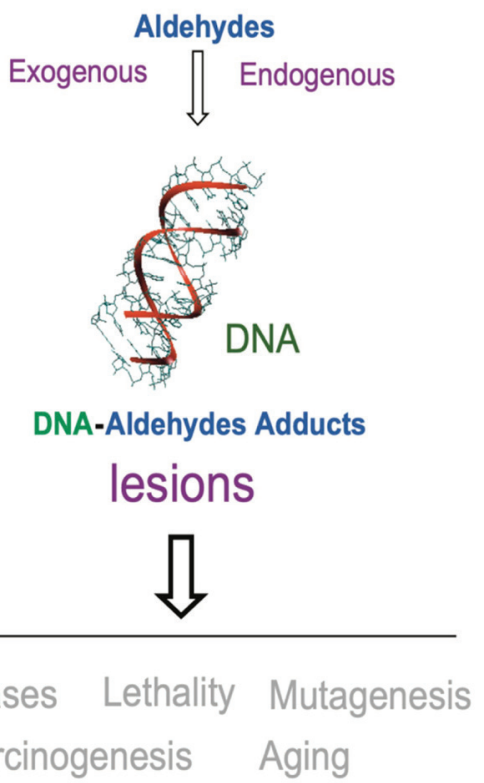

Figure 1. Biological consequences of DNA damage induced by exogenous and endogenous aldehydes. 
pollution exposure. Indeed, due to their potential adverse health effects, aldehydes are among the pollutants that arouse the greatest interest. It is important to note that air pollution was classified by the International Agency for Research on Cancer (IARC) as carcinogenic to humans (IARC Group 1).?

\section{The Lipid Peroxidation Process}

Lipid peroxidation is an important redox stress event that has been linked to the development of several pathologies such as cancer, as well as neurodegenerative and inflammatory diseases. The polyunsaturated fatty acid side chains of membrane phospholipids undergo enzymatic and non-enzymatic oxidation events, which are known to generate a complex mixture of phospholipid products, including hydroperoxides, that can decompose to electrophilic derivatives, such as aldehydes and epoxyaldehydes (Figure 2). ${ }^{8}$

The lipid peroxidation initiation involves abstraction of a bis-allylic hydrogen atom from $\omega-3$ and $\omega-6$ unsaturated fatty acids by an oxidant. This is followed by radical chain reaction, that leads to the formation of lipid hydroperoxides, intramolecular rearrangement and chain-breaking reactions. ${ }^{9}$ The decomposition of lipid hydroperoxides is important because, in addition to generating radicals that propagate the lipid peroxidation process, it also generates non-radical products (Figure 2). These by-products (alkanes, alkenes, aldehydes, ketones, hydroxy acids) are more stable than the free radicals that initiated the process and the lipid radicals formed during the propagation phase. Consequently, these non-radical products are more toxic because they can reach points distant from where they were formed. ${ }^{8}$ Biological systems contain a mixture of different polyunsaturated fatty acids with varying degrees of unsaturation. As a consequence, lipid peroxidation generates a mixture of lipid hydroperoxides, which can ultimately produce a variety of different aldehydes and radical species. ${ }^{10}$

Reactive aldehydes including 4-hydroxy-trans2-nonenal (HNE), 2,4-decadienal (DDE), malondialdehyde (MDA), ${ }^{9,11}$ 4-hydroperoxy-(2E)-nonenal (HPNE), 4-oxo(2E)-nonenal (ONE), 9,12-dioxo-(10E)-dodecenoic acid (DODE), 5,8-dioxo-(10E)-octenoic acid (DOOE), 4,5-epoxy-(2E)-decenal (EDE), hexenal, 2-propenal (acrolein), and crotonaldehyde ${ }^{11-13}$ are all formed as secondary lipid peroxidation products (Figure 3).

A growing number of studies have shown that aldehydes interact directly with DNA and cause genetic damage, or are metabolized to epoxides, compounds known to be alkylating agents of DNA with high mutagenic activity. ${ }^{14,15}$ The most extensively studied final products

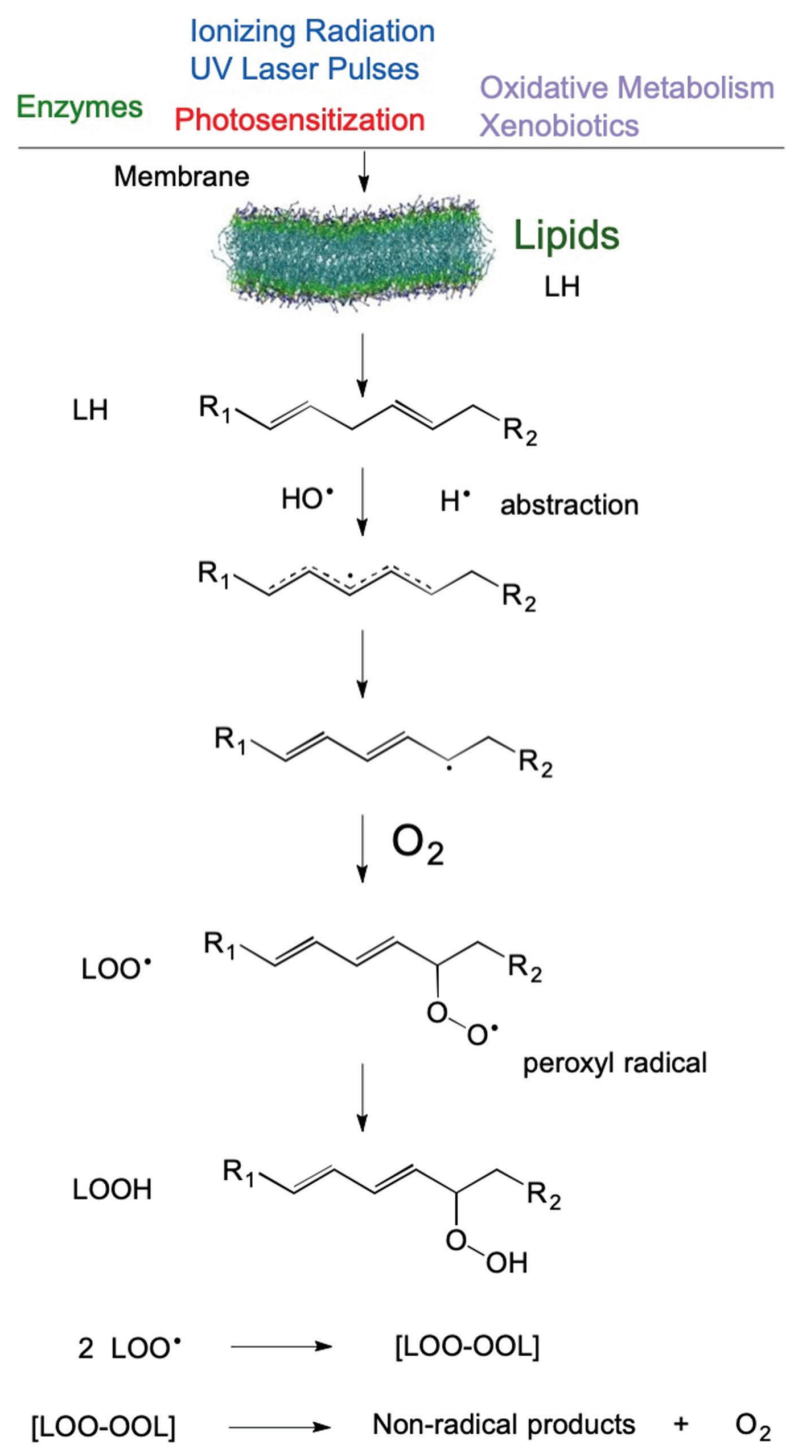

Figure 2. Representation of the initiation and propagation reactions of lipid peroxidation (LH: lipid; LOO: lipid peroxyl radical; LOOH: lipid hydroperoxide).

are the aldehydes, MDA and HNE. MDA is highly toxic to cells and has been considered a marker for lipid peroxidation. ${ }^{16} \mathrm{HNE}$ has been extensively studied because of its high reactivity with a large number of biomolecules. ${ }^{17}$ Additionally, it has many cytotoxic effects, such as the inhibition of enzyme activity, protein synthesis, DNA and ribonucleic acid (RNA) synthesis, as well as the induction of heat shock proteins and blockage of cell proliferation. ${ }^{17,18}$ HNE has also been shown to possess genotoxic ${ }^{19,20}$ and mutagenic properties. ${ }^{20}$ This aldehyde was also present in oil samples collected during the Spanish oil syndrome. ${ }^{11}$ It is well established that HNE is a strong electrophile which reacts preferentially with compounds having thiol groups (cysteine, glutathione, $\mathrm{SH}$-containing proteins), and is less reactive with compounds containing amino groups. ${ }^{4}$ On the 


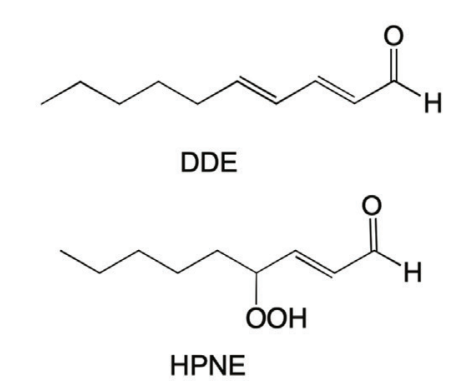<smiles>CCCCCC(O)/C=C/C=O</smiles><smiles>CCCCCC(=O)/C=C/C=O</smiles>
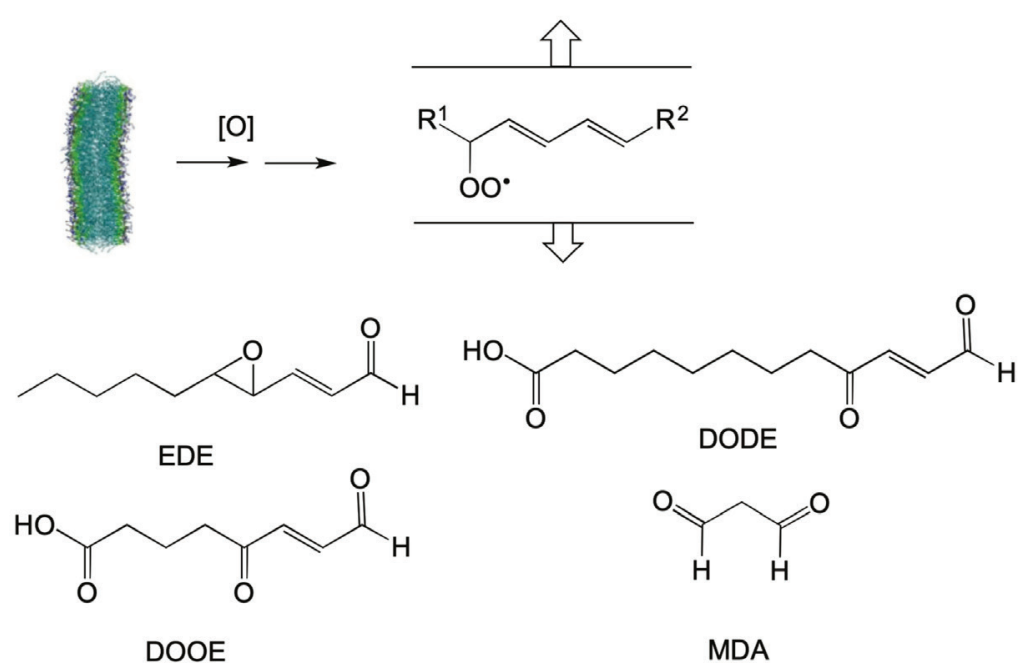

Figure 3. Some reactive aldehydes generated as secondary lipid peroxidation products. 4-Hydroxy-trans-2-nonenal (HNE), 2,4-decadienal (DDE), malondialdehyde (MDA), 4-hydroperoxy-(2E)-nonenal (HPNE), 4-oxo-(2E)-nonenal (ONE), 9,12-dioxo-(10E)-dodecenoic acid (DODE), 5,8-dioxo(10E)-octenoic acid (DOOE), 4,5-epoxy-(2E)-decenal (EDE).

other hand, it has been reported that another secondary lipid peroxidation product, the 4-oxo-2-nonenal, is more reactive with sulfhydryl groups than HNE and, is more reactive with DNA than other aldehydes. ${ }^{21}$

Kawai et al..$^{22}$ observed an increase in aldehydes in the liver of mice intraperitoneally injected with bromobenzene, an experimental animal model for lipid peroxidation; however, the authors pointed out that the types of aldehydes formed depends on which polyunsaturated fatty acids are present in the membrane. Therefore, these results indicate the importance of monitoring not only a specific aldehyde or the total amount of aldehydes, as in the TBARS (thiobarbituric acid reactive substances) assay, but also all individual aldehydes.

\section{Aldehyde-DNA Adducts}

Lesions produced from the reaction between aldehydes and DNA, generated during the lipid peroxidation process, have been detected at basal levels in human tissues (Figure 4). ${ }^{5,12,23}$ For example, MDA reacts with 2'-deoxyguanosine (dGuo), 2'-deoxyadenosine (dAdo) and 2'-deoxycytidine (dCyt), yielding the cyclic pyrimidopurinone 3-(2-deoxy- $\beta$-D-erythro-pentofuranosyl) pyrimido[1,2- $a$ purin- $10(3 H)$-one $\left(\mathrm{M}_{1} \mathrm{dG}\right)$, and the acyclic adducts $N^{6}$-(3-oxo-1-propenyl)-2'-deoxyadenosine $\left(\mathrm{M}_{1} \mathrm{dA}\right)$ and $N^{4}$-(3-oxo-1-propenyl)-2'-deoxycytidine $\left(\mathrm{M}_{1} \mathrm{dC}\right){ }^{24}$ Additionally, the promutagenic pyrimidopurinone adduct $\mathrm{M}_{1} \mathrm{dG}$ (Figure 4) has been detected in different human tissues. $^{25-28}$

The intake of dietary polyunsaturated fatty acids has been correlated with the formation of $\mathrm{M}_{1} \mathrm{dGuo}$ in female leukocytes..$^{29}$ Additionally, $\mathrm{M}_{1} \mathrm{dGuo}$, ranging from 0.004 to 9.15 adducts per $10^{8}$ nucleotides, was detected in human leukocyte DNA, by liquid chromatographynanoelectrospray ionization high-resolution tandem mass spectrometry. ${ }^{30}$ The $\mathrm{M}_{1} \mathrm{dGuo}$ adduct is oxidized to 6-oxo$\mathrm{M}_{1} \mathrm{dGuo}$ in genomic DNA of intact cells, which suggests a possible role of 6-oxo- $\mathrm{M}_{1} \mathrm{dGuo}$ in the consequences attributed to $\mathrm{M}_{1} \mathrm{dGuo}$ in biological systems. ${ }^{31}$ Interestingly, elevated levels of the MDA-dGuo adducts were present in DNA extracted from the nasal mucosa of children from an industrial city, in Italy. ${ }^{32}$

Highly reactive $\alpha, \beta$-unsaturated aldehydes, such as acrolein, crotonaldehyde, and trans-4-hydroxy-2-nonenal (HNE), were found to react with DNA aminobases, yielding cyclic adducts. ${ }^{33-35}$ Cyclic adducts are formed by Michael addition at the exocyclic amino group, followed by ring 
<smiles>CC(C)n1cnc2c1ncn1ccnc21</smiles><smiles>CCCn1ccc2nccn2c1=O</smiles>
$\varepsilon \mathrm{dAdo}$ $\varepsilon \mathrm{dCyd}$<smiles>O=c1[nH]c2nccn2c2c1ncn2[TlH]</smiles>

$N^{2}, 3-\varepsilon d G u o$<smiles>CCCn1cnc2c(=O)n3cc[nH]c3nc21</smiles>

$1, N^{2}-\varepsilon d G u o$<smiles>CCCn1cnc2c(=O)n3cccnc3nc21</smiles>

$M_{1} G$ (dGuo)<smiles>O=c1c2ncn([Tl])c2nc2n1[C@H](O)CCN2</smiles>

OH-PdGuo<smiles>CCCCCC(O)C1CC(O)n2c(nc3c(ncn3[GaH])c2=O)N1</smiles>

HNE-derived 1, $N^{2}$-PdGuo

Figure 4. Structure of exocyclic DNA adducts formed by the reaction of DNA with aldehyde.

closure. ${ }^{5,36}$ Basal levels of 1, $N^{2}$-propano-2'-deoxyguanosine $\left(1, N^{2}\right.$-propanodGuo) adducts resulting from the reaction of acrolein, crotonaldehyde, and HNE have been detected in DNA of rodents and human tissues. ${ }^{37-39}$ Accurate determinations of $1, N^{2}$-propanodGuo levels in DNA extracts of cultured human cells ( $3.43 \pm 0.33$ per $10^{8} \mathrm{dGuo}$ ) and rat tissue (liver, $4.61 \pm 0.69$ per $10^{8} \mathrm{dGuo}$; brain, $5.66 \pm 3.70$ per $10^{8} \mathrm{dGuo}$; and lung, and $2.25 \pm 1.72$ per $10^{8} \mathrm{dGuo}$ ) have been performed by online high performance liquid chromatography-electrospray ionizationtandem mass spectrometry (HPLC-ESI-MS/MS). ${ }^{40}$ Additionally, 1, $N^{2}$-propanodGuo adducts levels (2.4-3.5 adducts per $10^{8}$ nucleotides) were detected in untreated human embryonic lung fibroblast MRC5 cells, and these levels increase in a concentration-dependent manner after treatment with crotonaldehyde. ${ }^{41}$

The epoxy carbonyl compounds resulting from the oxidation $\alpha, \beta$-unsaturated aldehydes, upon reaction with DNA, can generate ethano or etheno adducts (Figure 4). ${ }^{5,42,43}$ In fact, in vitro studies have shown that etheno adducts are genotoxic and mutagenic by primer extension assays and in vivo by site-specific mutagenesis analyses in cells. ${ }^{44}$ For example, 2,4-decadienal, one of the most toxic lipid hydroperoxide breakdown products to cells, ${ }^{45}$ generates $1, N^{6}$-etheno-2'-deoxyadenosine (EdAdo), $1, N^{2}$-etheno2-deoxyguanosine (1, $\left.N^{2}-\varepsilon \mathrm{dGuo}\right)$ and six different etheno derivative adducts in the reaction between dAdo or dGuo and 2,4-decadienal-epoxides (Figure 5). ${ }^{46,47}$ 2,4-Decadienal has been shown to be cytotoxic to human erythroleukemia cells. Indeed, previous work ${ }^{48}$ demonstrated that it inhibits cell growth, affects cell viability, changes the cellular glutathione levels, and is involved in DNA fragmentation. Furthermore, it has been shown that 2,4-decadienal exerts lethal effects on human diploid fibroblasts and umbilical vein endothelial cells. ${ }^{45,49}$

Increased levels of edAdo and $\varepsilon \mathrm{dCyd}$ were observed in clinical situations associated with oxidative stress, such as metal storage diseases, chronic infections and inflammation. ${ }^{23,50}$ The number of these lesions was also elevated in colon polyps of patients with familial adenomatous polyposis, who later develop carcinomas in the colon. ${ }^{51}$ In addition, these adducts are augmented in the white blood cell DNA of women consuming diets rich in polyunsaturated fatty acids..$^{52}$ Therefore, etheno adducts have been employed as markers for DNA damage produced during lipid peroxidation. ${ }^{53}$

The genotoxicity and mutagenicity of etheno adducts have been demonstrated by in vitro primer extension assays and by site-specific mutagenesis in vivo. ${ }^{54}$ It has also been shown that heptanone-substituted $3, N^{4}$-etheno2'-deoxycytidine (heptanone- $\varepsilon \mathrm{dCyd}$ ) blocks DNA synthesis and increases miscoding in both bacteria and human cells..$^{55}$

\section{Endogenous and Exogenous Acetaldehyde}

Acetaldehyde is commonly found in foods, beverages, cigarette smoke and fuel combustion, and, consequently, widespread throughout the environment. ${ }^{7}$ Acetaldehyde is a mutagenic and carcinogenic compound capable of inducing mutations ( $\mathrm{G} \rightarrow \mathrm{A}$ transitions and $\mathrm{G} \rightarrow \mathrm{T}$ transversions), and sister chromatid exchanges in rodent spinal cord cells, squamous epithelium and cultured human lymphocytes. ${ }^{7,56,57}$ 
Unsubstituted etheno adducts<smiles>[R]n1cnc2c(=O)[nH]c3nccn3c21</smiles>

$N^{2}, 3-\varepsilon d G u o$<smiles>[R]n1cnc2c(=O)n3cc[nH]c3nc21</smiles>

$1, N^{2}-\varepsilon d G u o$<smiles>[R]n1cnc2c1ncn1ccnc21</smiles>

$\varepsilon d A d o$<smiles>O=c1n([Ga])ccc2nccn12</smiles>

$\varepsilon \mathrm{dCyd}$

\section{Substituted ethano or etheno adducts}

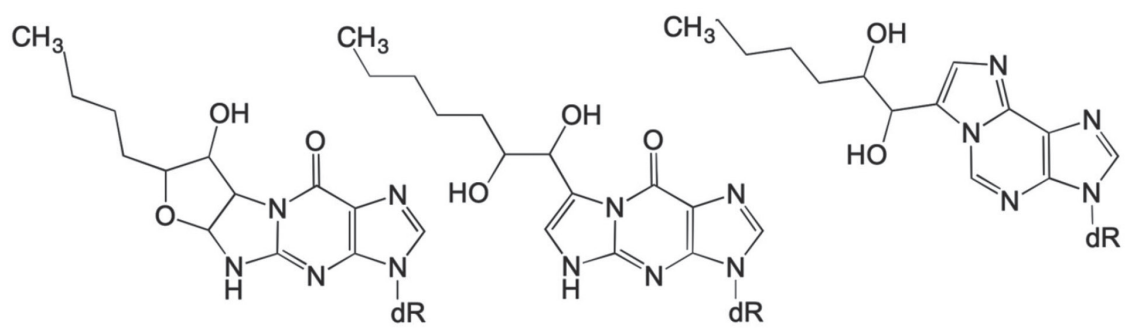

HNE-dGuo adducts

HNE-dAdo adduct

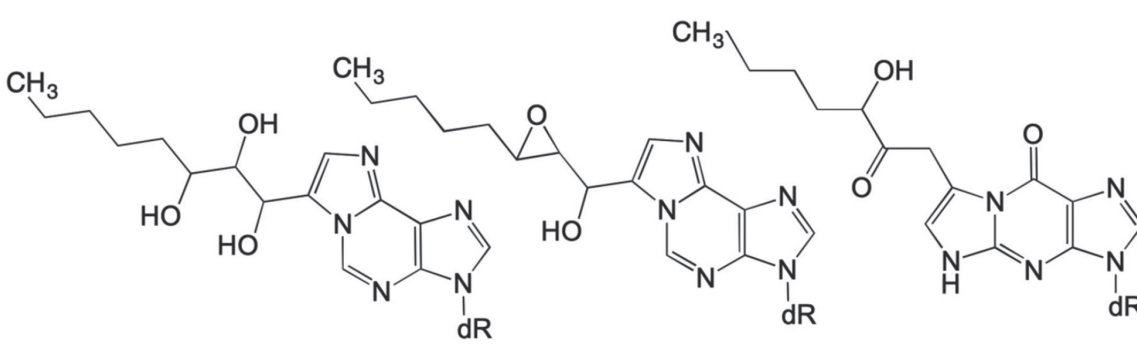

DDE-dAdo adducts

DDE-dGuo adduct

$\mathrm{dR}=$ 2-deoxyribose

Figure 5. Structures of substituted and unsubstituted ethano or etheno adducts ( $\varepsilon$ dAdo: 1, $N^{6}$-etheno-2'-deoxyadenosine; $\varepsilon$ dCyd: $3, N^{4}$-etheno-2'-deoxycytidine;

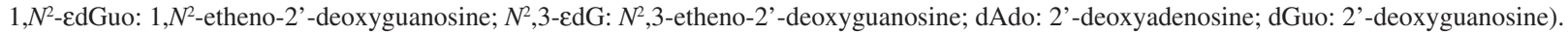

Acetaldehyde is carcinogenic to rats and hamsters, inducing respiratory tract tumors after inhalation..$^{58}$ It is formed endogenously as a product of ethanol oxidation and has been found in the liver and saliva after ethanol ingestion..$^{59,60}$ Acetaldehyde is also produced in small amounts during threonine catabolism. ${ }^{61}$ It is noteworthy that populations deficient in aldehyde dehydrogenase have a higher risk of developing esophageal cancer associated with alcohol consumption, when compared to populations with fully active enzyme. ${ }^{62,63}$ The formation of DNA adducts has been considered to be a key factor in the acetaldehyde toxicity mechanism. ${ }^{64}$ This compound has also been shown to react with DNA. For example, when acetaldehyde reacts with 2'-deoxyguanosine (dGuo), $N^{2}$-ethylidene2'-deoxyguanosine ( $N^{2}$-ethyldGuo), and an unstable Schiff base are formed. ${ }^{65}$ The $N^{2}$-ethyldGuo can then react with a second molecule of acetaldehyde forming the $(6 S, 8 S)$ and $(6 R, 8 R)$ diastereomers of $1, N^{2}$-propanodGuo adducts (Figure 6). ${ }^{66}$

The formation of $1, N^{2}$-propanodGuo, as a two-step reaction, was unequivocally demonstrated by treating cells with $\left[{ }^{13} \mathrm{C}_{2}\right]$-acetaldehyde and detecting the labeled adduct with HPLC-ESI-MS/MS (Figure 7). ${ }^{67}$

The reduced form of $N^{2}$-ethylidenedGuo was also quantified in DNA from cells treated with $\left[{ }^{13} \mathrm{C}_{2}\right]$-acetaldehyde, and it was observed that these adducts were present at levels comparable to those of $1, N^{2}$-propanodGuo. A similar result was also reported in cells exposed to high concentrations of acetaldehyde. ${ }^{68} \mathrm{It}$ was suggested that the formation of $1, N^{2}$-propanodGuo 


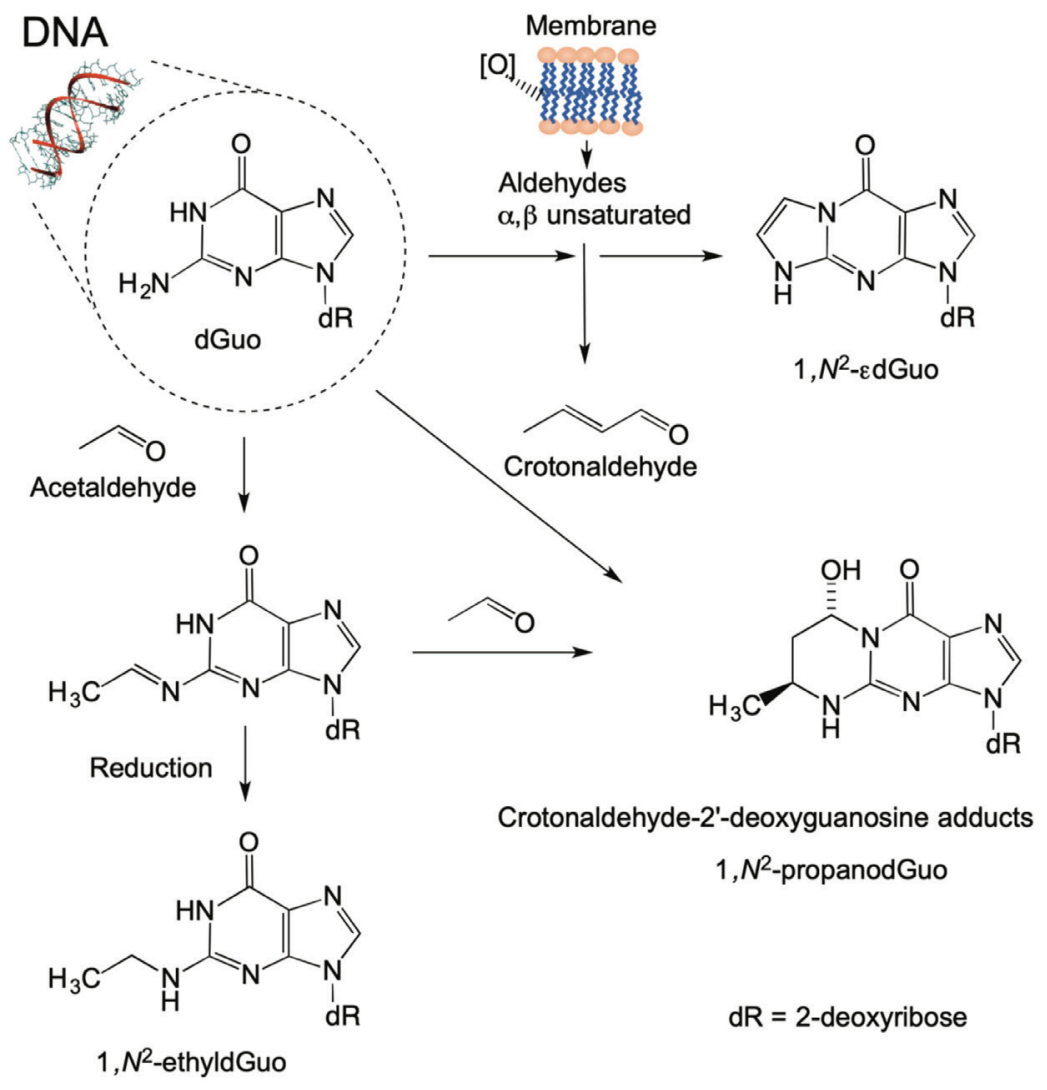

Figure 6. Formation of 1, $N^{2}$-propanodGuo from acetaldehyde and crotonaldehyde.
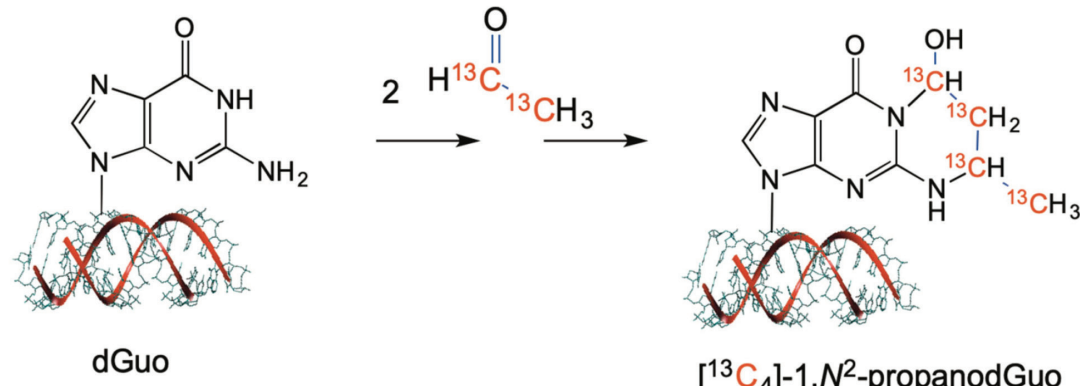

$\left[{ }^{13} \mathrm{C}_{4}\right]-1, N^{2}$-propanodGuo

Figure 7. Reaction of 2'-deoxyguanosine (dGuo) with two molecules of $\left[{ }^{13} \mathrm{C}_{2}\right]$-acetaldehyde.

was unfavorable at low acetaldehyde concentrations, and that $N^{2}$-ethylidenedGuo formed at higher rates. Therefore $N^{2}$-ethylidenedGuo should be the main adduct formed under typical human exposure conditions. ${ }^{67}$

Polyamines and histones catalyze the formation of $1, N^{2}$-propanodGuo. The reaction of crotonaldehyde with dGuo, as well as with DNA forms $1, N^{2}$-propanodGuo. In addition to being an industrial pollutant, crotonaldehyde is also produced by the lipid peroxidation and is a metabolite of N-nitrosopyrrolidine. ${ }^{69} \mathrm{In}$ DNA, the $1, N^{2}$-propanodGuo adduct exists in equilibrium between open and closed forms. The open form is favored in double-stranded DNA, whereas the closed form predominates in single-stranded DNA. ${ }^{70}$
Interestingly, high levels of $1, N^{2}$-propanodGuo (20.8 fmol of $1, N^{2}$-propanodGuo per $\mathrm{mg}$ creatinine) were found in the urine of residents living in a polluted region of São Paulo City, in Brazil, when compared with urine from residents of an unpolluted Brazilian city (São João da Boa Vista, São Paulo State) (7.9 fmol of $1, N^{2}$-propanodGuo per mg creatinine).$^{71}$

Air pollution has been associated with increased mortality among various age groups and responsible for causing several adverse health effects. ${ }^{72}$ The investigation of the mutagenicity of organic solvent extracts of $\mathrm{PM}_{10}$ (particulate matter with aerodynamic diameters of less than $10 \mu \mathrm{m}$ ) collected from SP was performed by de Martinis et al. ${ }^{73}$ and found that the most mutagenic extract 
fractions contained aldehydes, ketones, carboxylic acids and quinolines. Recently, it was shown that mice exposed daily to $\mathrm{PM}_{2.5}$ (particulate matter with aerodynamic diameters of less than $2.5 \mu \mathrm{m}$ ), for 3 months, at a concentration that mimics a $24 \mathrm{~h}$ exposure to the mean concentration found in ambient air presented, after 3 months, increased levels of DNA lesions consistent with oxidative stress in the lungs, liver and kidney. Additionally, it has been proposed that genetic and epigenetic alterations induced by pollutants may increase the chance of cancer development. ${ }^{74}$

Studies with inhaled acetaldehyde in animal models, have been performed since 1900, when the anesthetic properties of aldehyde in animals was shown by Lewin. ${ }^{75}$ Subsequent, studies have demonstrated the carcinogenic effects of acetaldehyde in different animal models breathing very high concentrations of acetaldehyde. ${ }^{76}$ Furthermore, rats chronically exposed ( $6 \mathrm{~h}$ per day, five days a week for 52 weeks) to acetaldehyde concentrations of greater than 400 ppm displayed degeneration of the olfactory epithelium. At higher acetaldehyde concentrations, effects ranging from hyper-and metaplasia of olfactory epithelium cells to the development of cancer (squamous cell and adenocarcinomas) were reported..$^{58,77,78}$

The unequivocal formation of labeled $1, N^{2}$-propanodGuo in DNA was also verified, by micro-HPLC-MS/MS, in the lung and brain tissues of rats that inhaled environmentally relevant doses of $\left[{ }^{13} \mathrm{C}_{2}\right]$-acetaldehyde. Additionally, the structure of the products was confirmed by nanoflow high-performance liquid chromatography-electrospray ionization high resolution tandem mass spectrometry in the positive mode ${ }^{3}$ analyses. Together these results indicated that the levels of the $1, N^{2}$-propanodGuo adduct could be potentially utilized as a biomarker of acetaldehyde and crotonaldehyde exposure, and that monitoring these levels could protect the exposed population against the related adverse effects of this chemical. ${ }^{79}$

\section{DNA-Adducts Quantification in vivo}

Efforts have been made to determine the levels of exocyclic DNA adducts generated by exposure to electrophilic molecules, from both exogenous and endogenous sources. Indeed, in vivo studies showed that endogenous sources generated approximately 0-20 lesions per $10^{8}$ nucleotides. ${ }^{12,23,80}$ Due to the extremely low levels of these adducts in biological systems, ultrasensitive methods are required for their detection and quantification. ${ }^{5}$ Examples of such techniques include immunoassays, ${ }^{32} \mathrm{P}$-postlabeling, gas chromatography-mass spectrometry (GC-MS), and liquid chromatography-tandem mass spectrometry (LCMS/MS). Among these ultrasensitive methods, LC-MS/
MS is considered to be the most precise and specific method for quantifying exocyclic DNA adducts. The confidence level of this method can be further improved by including an isotopically labeled internal standard prior to DNA hydrolysis, which allows for the correction of any analyte loss during the procedure. In fact, the current mass spectrometry technology is capable of quantifying exocyclic DNA adducts in the range of 10-18 amol. ${ }^{79}$

\section{Mechanism of in vivo Aldehyde Detoxifica- tion}

Endogenous and exogenous aldehydes are metabolized to less toxic products by oxidation / reduction (phase I) or conjugation (phase II) mechanisms. The phase I mechanism employs enzymes such as glutathione S-transferase (GST), aldehyde dehydrogenase (ALDH), aldo-keto reductase (AKR), cytochrome P450 and alcohol dehydrogenase, which are directly involved in aldehyde detoxification. ${ }^{81,82} \mathrm{~A}$ wellknown phase II mechanism for aldehyde detoxification in cells involves the conjugation of these aldehydes with glutathione (GSH), which yields Michael adducts. Additionally, endogenous histidine-containing dipeptides such as carnosine ( $\beta$-alanyl-L-histidine, CAR), homocarnosine ( $\gamma$-amino-butyryl-histidine) and anserine $(\beta$-alanylL-1-methylhistidine) have been shown to detoxify aldehydes through phase II mechanisms. ${ }^{83}$ Moreover, carnosine has been found at high concentrations in skeletal muscle, as well as in the central nervous system. ${ }^{84}$ However, $\beta$-alanine availability is a limiting factor for carnosine synthesis, and $\beta$-alanine supplementation has been shown to increase carnosine content in skeletal muscle. ${ }^{85-87}$ Interestingly, it was shown that administering carnosine ( $2 \mathrm{~g}$ per day) to overweight individuals resulted in a significant increase in the amount of carnosine-acrolein adducts excreted in the urine. ${ }^{88}$ In fact, our group elucidated the structure of a 3-methylpyridinium carnosine, resulting from the reaction between carnosine and acrolein, and simultaneously quantified carnosine-aldehyde adducts in human urine. ${ }^{89}$ Recently, carnosine-aldehyde adducts were quantified by LC-MS/MS in human skeletal muscle samples after acute exercise, before and after $\beta$-alanine supplementation..$^{90}$ This study demonstrated that there was a significant increase in post-exercise carnosineacrolein levels following $\beta$-alanine supplementation, whereas neither exercise or supplementation alone increased the formation of this adduct.

\section{Conclusions}

A variety of chemicals have been shown to alkylate DNA bases. In fact, some of these modifications are formed 
in human tissues after exposure to reactive aldehydes, resulting in the formation of exocyclic adducts. DNA adducts produced by exogenous and endogenous aldehydes are currently becoming recognized as potential tools for studying a variety of human diseases, as well as the effects of air pollution exposure. However, a systematic investigation of these lesions is necessary for identifying which type of lesion is the most critical in each situation. Ultra-sensitive mass spectrometry techniques have been utilized for understanding the mechanisms involved in the generation of these adducts, as well as for the identification of novel biomarkers associated with these modifications. Advances in mass spectrometry technology are improving exocyclic DNA adduct detection, especially in the blood and urine, which may provide novel noninvasive clinically applicable assays.

\section{Acknowledgments}

Supported by CEPID-Redoxoma (FAPESP process No. 2013/07937-8), NAP-Redoxoma (Pró-Reitoria de Pesquisa-USP process No. 2011.1.9352.1.8), CNPq (process No. 301404/2016-0) and Universidade de São Paulo.

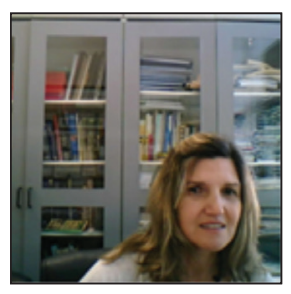

Marisa Helena G. de Medeiros earned her bachelor degree in Chemistry and her PhD in Biochemistry at the Instituto de Química, Universidade de São Paulo (IQ-USP), Brazil. She performed postdoctoral studies at University of Düsseldorf. In 1988, she returned to Brazil, where she is a Full Professor of Biochemistry at the IQ-USP since 1988. Her current focus is to understand how reactive aldehydes react with specific biomolecules and the resulting effects, essential for designing biomarkers.

\section{References}

1. Gates, K. S.; Chem. Res. Toxicol. 2009, 22, 1747.

2. Tubbs, A.; Nussenzweig, A.; Cell 2017, 168, 644.

3. O’Brien, P. J.; Siraki, A. G.; Shangari, N.; Crit. Rev. Toxicol. 2005, 35, 609.

4. LoPachin, R. M.; Gavin, T.; Chem. Res. Toxicol. 2014, 27, 1081.

5. Medeiros, M. H. G.; Chem. Res. Toxicol. 2009, 22, 419.

6. Petersen, D. R.; Doorn, J. A.; Free Radicals Biol. Med. 2004, 37, 937.

7. International Agency for Research on Cancer (IARC); Monographs on the Evaluation of the Carcinogenic Risk of Chemicals to Humans, vol. 109; IARC Working Group on the
Evaluation of Carcinogenic Risks to Humans: Lyon, 2016, p. 449.

8. West, J. D.; Marnett, L. J.; Chem. Res. Toxicol. 2006, 19, 173.

9. Ullery, J. C.; Marnett, L. J.; Biochim. Biophys. Acta, Biomembr. 2012, 1818, 2424.

10. Yin, H.; Xu, L.; Porter, N. A.; Chem. Rev. 2011, 111, 5944.

11. Esterbauer, H.; Schaur, R. J.; Zollner, H.; Free Radicals Biol. Med. 1991, 11, 81.

12. Blair, I. A.; J. Biol. Chem. 2008, 283, 15545.

13. Benedetti, A.; Comporti, M.; Fulceri, R.; Esterbauer, H.; Biochim. Biophys. Acta 1984, 792, 172.

14. Basu, A. K.; Wood, M. L.; Niedernhofer, L. J.; Ramos, L. A.; Essigmann, J. M.; Biochemistry 1993, 32, 12793.

15. Pandya, G. A.; Moriya, M.; Biochemistry 1996, 35, 11487.

16. VanderVeen, L. A.; Hashim, M. F.; Shyr, Y.; Marnett, L. J.; Proc. Natl. Acad. Sci. U. S. A. 2003, 100, 14247.

17. Schaur, R. J.; Mol. Aspects Med. 2003, 24, 149.

18. Csala, M.; Kardon, T.; Legeza, B.; Lizak, B.; Mandl, J.; Margittai, E.; Puskas, F.; Szaraz, P.; Szelenyi, P.; Banhegyi, G.; Biochim. Biophys. Acta, Mol. Basis Dis. 2015, 1852, 826.

19. Eckl, P. M.; Mol. Aspects Med. 2003, 24, 161.

20. Zhong, H. Q.; Yin, H. Y.; Redox Biol. 2015, 4, 193.

21. Lin, D.; Lee, H. G.; Liu, Q.; Perry, G.; Smith, M. A.; Sayre, L. M.; Chem. Res. Toxicol. 2005, 18, 1219.

22. Kawai, Y.; Takeda, S.; Terao, J.; Chem. Res. Toxicol. 2007, $20,99$.

23. Nair, U.; Bartsch, H.; Nair, J.; Free Radicals Biol. Med. 2007, 43, 1109.

24. Stone, K.; Uzieblo, A.; Marnett, L. J.; Chem. Res. Toxicol. 1990, $3,467$.

25. Vaca, C. E.; Fang, J. L.; Mutanen, M.; Valsta, L.; Carcinogenesis 1995, 16, 1847.

26. Chaudhary, A. K.; Reddy, G. R.; Blair, I. A.; Marnett, L. J.; Carcinogenesis 1996, 17, 1167.

27. Wang, M. Y.; Dhingra, K.; Hittelman, W. N.; Liehr, J. G.; de Andrade, M.; Li, D. H.; Cancer Epidemiol., Biomarkers Prev. 1996, 5, 705 .

28. Rouzer, C. A.; Chaudhary, A. K.; Nokubo, M.; Ferguson, D. M.; Reddy, G. R.; Blair, I. A.; Marnett, L. J.; Chem. Res. Toxicol. 1997, 10, 181.

29. Fang, J. L.; Vaca, C. E.; Valsta, L. M.; Mutanen, M.; Carcinogenesis 1996, 17, 1035.

30. Ma, B.; Villalta, P. W.; Balbo, S.; Stepanov, I.; Chem. Res. Toxicol. 2014, 27, 1829.

31. Wauchope, O. R.; Beavers, W. N.; Galligan, J. J.; Mitchener, M. M.; Kingsley, P. J.; Marnett, L. J.; Chem. Res. Toxicol. 2015, 28, 2334.

32. Peluso, M.; Munnia, A.; Ceppi, M.; Giese, R. W.; Catelan, D.; Rusconi, F.; Godschalk, R. W. L.; Biggeri, A.; Mutagenesis 2013, 28, 315 .

33. Smith, R. A.; Williamson, D. S.; Cerny, R. L.; Cohen, S. M.; Cancer Res. 1990, 50, 3005. 
34. Eder, E.; Hoffman, C.; Chem. Res. Toxicol. 1992, 5, 802.

35. Sodum, R. S.; Chung, F. L.; Cancer Res. 1988, 48, 320.

36. Chung, F. L.; Young, R.; Hecht, S. S.; Cancer Res. 1984, 44, 990.

37. Nath, R. G.; Ocando, J. E.; Chung, F. L.; Cancer Res. 1996, 56, 452.

38. Chung, F. L.; Nath, R. G.; Ocando, J.; Nishikawa, A.; Zhang, L.; Cancer Res. 2000, 60, 1507.

39. Wacker, M.; Schuler, D.; Wanek, P.; Eder, E.; Chem. Res. Toxicol. 2000, 13, 1165.

40. Garcia, C. C. M.; Freitas, F. P.; di Mascio, P.; Medeiros, M. H. G.; Chem. Res. Toxicol. 2010, 23, 1851.

41. Zhang, N.; Song, Y. Y.; Wu, D. N.; Xu, T.; Lu, M. L.; Zhang, W. B.; Wang, H. L.; J. Chromatogr. A 2016, 1450, 38.

42. Doerge, D. R.; Churchwell, M. I.; Fang, J. L.; Beland, F. A.; Chem. Res. Toxicol. 2000, 13, 1259.

43. Morinello, E. J.; Ham, A. J. L.; Ranasinghe, A.; Sangaiah, R.; Swenberg, J. A.; Chem. Res. Toxicol. 2001, 14, 327.

44. Barbin, A.; Mutat. Res., Rev. Mutat. Res. 2000, 462, 55.

45. Kaneko, T.; Kaji, K.; Matsuo, M.; Chem.-Biol. Interact. 1988, 67, 295.

46. Carvalho, V. M.; Asahara, F.; di Mascio, P.; Campos, I. P. D.; Cadet, J.; Medeiros, M. H. G.; Chem. Res. Toxicol. 2000, 13, 397.

47. Loureiro, A. P. M.; Arruda-Campos, I. P.; di Mascio, P.; Medeiros, M. H. G.; Free Radicals Biol. Med. 2002, 33, S57.

48. Nappez, C.; Battu, S.; Beneytout, J. L.; Cancer Lett. 1996, 99 , 115.

49. Kaneko, T.; Honda, S.; Nakano, S.; Matsuo, M.; Chem.-Biol. Interact. 1987, 63, 127.

50. Nair, J.; Gal, A.; Tamir, S.; Tannenbaum, S. R.; Wogan, G. N.; Bartsch, H.; Carcinogenesis 1998, 19, 2081.

51. Schmid, K.; Nair, J.; Winde, G.; Velic, I.; Bartsch, H.; Int. J. Cancer 2000, 87, 1.

52. Nair, J.; Vaca, C. E.; Velic, I.; Mutanen, M.; Valsta, L. M.; Bartsch, H.; Cancer Epidemiol., Biomarkers Prev. 1997, 6, 597.

53. Arab, K.; Pedersen, M.; Nair, J.; Meerang, M.; Knudsen, L. E.; Bartsch, H.; Carcinogenesis 2009, 30, 282.

54. Gros, L.; Ishchenko, A. A.; Saparbaev, M.; Mutat. Res., Fundam. Mol. Mech. Mutagen. 2003, 531, 219.

55. Pollack, M.; Yang, I. Y.; Kim, H. Y. H.; Blair, I. A.; Moriya, M.; Chem. Res. Toxicol. 2006, 19, 1074.

56. Mizumoto, A.; Ohashi, S.; Hirohashi, K.; Amanuma, Y.; Matsuda, T.; Muto, M.; Int. J. Mol. Sci. 2017, 18, 1943.

57. Secretan, B.; Straif, K.; Baan, R.; Grosse, Y.; el Ghissassi, F.; Bouvard, V.; Benbrahim-Tallaa, L.; Guha, N.; Freeman, C.; Galichet, L.; Cogliano, V.; Monograph, W. I. A. R. C.; Lancet Oncol. 2009, 10, 1033.

58. Woutersen, R. A.; Appelman, L. M.; Feron, V. J.; van der Heijden, C. A.; Toxicology 1984, 31, 123.

59. Visapaa, J. P.; Gotte, K.; Benesova, M.; Li, J.; Homann, N.;
Conradt, C.; Inoue, H.; Tisch, M.; Horrmann, K.; Vakevainen, S.; Salaspuro, M.; Seitz, H. K.; Gut 2004, 53, 871.

60. Yokoyama, A.; Tsutsumi, E.; Imazeki, H.; Suwa, Y.; Nakamura, C.; Mizukami, T.; Yokoyama, T.; Alcohol.: Clin. Exp. Res. 2008, 32, 1607.

61. Ogawa, H.; Gomi, T.; Fujioka, M.; Int. J. Biochem. Cell Biol. 2000, 32, 289.

62. Matsuda, T.; Yabushita, H.; Kanaly, R. A.; Shibutani, S.; Yokoyama, A.; Chem. Res. Toxicol. 2006, 19, 1374.

63. Ogawa, M.; Oyama, T.; Isse, T.; Saito, K.; Tomigahara, Y.; Endo, Y.; Kawamoto, T.; Toxicol. Lett. 2007, 168, 148.

64. Brooks, P. J.; Theruvathu, J. A.; Alcohol 2005, 35, 187.

65. Wang, M.; McIntee, E. J.; Cheng, G.; Shi, Y. L.; Villalta, P. W.; Hecht, S. S.; Chem. Res. Toxicol. 2000, 13, 1149.

66. Hecht, S. S.; McIntee, E. J.; Wang, M.; Toxicology 2001, 166, 31.

67. Garcia, C. C. M.; Angeli, J. P. F.; Freitas, F. P.; Gomes, O. F.; de Oliveira, T. F.; Loureiro, A. P. M.; di Mascio, P.; Medeiros, M. H. G.; J. Am. Chem. Soc. 2011, 133, 9140.

68. Inagaki, S.; Esaka, Y.; Deyashiki, Y.; Sako, M.; Goto, M.; J. Chromatogr. A 2003, 987, 341 .

69. Wang, M. Y.; Nishikawa, A.; Chung, F. L.; Chem. Res. Toxicol. 1992, 5, 528.

70. Kurtz, A. J.; Lloyd, R. S.; J. Biol. Chem. 2003, 278, 5970.

71. Garcia, C. C. M.; Freitas, F. P.; Gomes, O. F.; di Mascio, P.; Medeiros, M. H. G.; Free Radicals Biol. Med. 2009, 47, S75.

72. Dockery, D. W.; Ann. Epidemiol. 2009, 19, 257.

73. de Martinis, B. S.; Kado, N. Y.; de Carvalho, L. R.; Okamoto, R. A.; Gundel, L. A.; Mutat. Res. 1999, 446, 83.

74. de Oliveira, A. A. F.; de Oliveira, T. F.; Dias, M. F.; Medeiros, M. H. G.; di Mascio, P.; Veras, M.; Lemos, M.; Marcourakis, T.; Saldiva, P. H. N.; Loureiro, A. P. M.; Part. Fibre Toxicol. 2018, $15,40$.

75. Lewin, L.; Arch. Exp. Pathol. Pharmakol. 1900, 43, 351.

76. Shiohara, E.; Tsukada, M.; Chiba, S.; Yamazaki, H.; Nishiguchi, K.; Miyamoto, R.; Nakanishi, S.; Toxicology 1984, 30, 25.

77. Appelman, L. M.; Woutersen, R. A.; Feron, V. J.; Toxicology 1982, 23, 293.

78. Woutersen, R. A.; Appelman, L. M.; van Garderen-Hoetmer, A.; Feron, V. J.; Toxicology 1986, 41, 213.

79. Sanchez, A. B.; Garcia, C. C. M.; Freitas, F. P.; Batista, G. L.; Lopes, F. S.; Carvalho, V. H.; Ronsein, G. E.; Gutz, I. G. R.; di Mascio, P.; Medeiros, M. H. G.; Chem. Res. Toxicol. 2018, 31, 332.

80. Dedon, P. C.; DeMott, M. S.; Elmquist, C. E.; Prestwich, E. G.; McFaline, J. L.; Pang, B.; Biomarkers Med. 2007, 1, 293.

81. Baba, S. P.; Hoetker, J. D.; Merchant, M.; Klein, J. B.; Cai, J.; Barski, O. A.; Conklin, D. J.; Bhatnagar, A.; J. Biol. Chem. 2013, 288, 28163.

82. Xie, Z. Z.; Baba, S. P.; Sweeney, B. R.; Barski, O. A.; Chem.Biol. Interact. 2013, 202, 288. 
83. Yeum, K. J.; Orioli, M.; Regazzoni, L.; Carini, M.; Rasmussen, H.; Russell, R. M.; Aldini, G.; Amino Acids 2010, 38, 847.

84. Boldyrev, A. A.; Aldini, G.; Derave, W.; Physiol. Rev. 2013, 93, 1803.

85. Hipkiss, A. R.; Exp. Gerontol. 2009, 44, 237.

86. Vistoli, G.; Carini, M.; Aldini, G.; Amino Acids 2012, 43, 111.

87. Orioli, M.; Aldini, G.; Benfatto, M. C.; Facino, R. M.; Carini, M.; Anal. Chem. 2007, 79, 9174.

88. Regazzoni, L.; de Courten, B.; Garzon, D.; Altomare, A.; Marinello, C.; Jakubova, M.; Vallova, S.; Krumpolec, P.; Carini,
M.; Ukropec, J.; Ukropcova, B.; Aldini, G.; Sci. Rep. 2016, 6, 27224.

89. Bispo, V. S.; Campos, I. P. D. A.; di Mascio, P.; Medeiros, M. H. G.; Sci. Rep. 2016, 6, 19348.

90. Carvalho, V. H.; Oliveira, A. H. S.; de Oliveira, L. F.; da Silva, R. P.; di Mascio, P.; Gualano, B.; Artioli, G. G.; Medeiros, M. H. G.; Redox Biol. 2018, 18, 222.

Submitted: February 1, 2019 Published online: April 9, 2019 